\title{
Career awareness and part-time work examined in lives of high school seniors
}

\author{
Marc T. Braverman = Jane Chin Young $=$ Nicelma J. King \\ Carole A. Paterson $=$ Robert S. Weisskirch
}

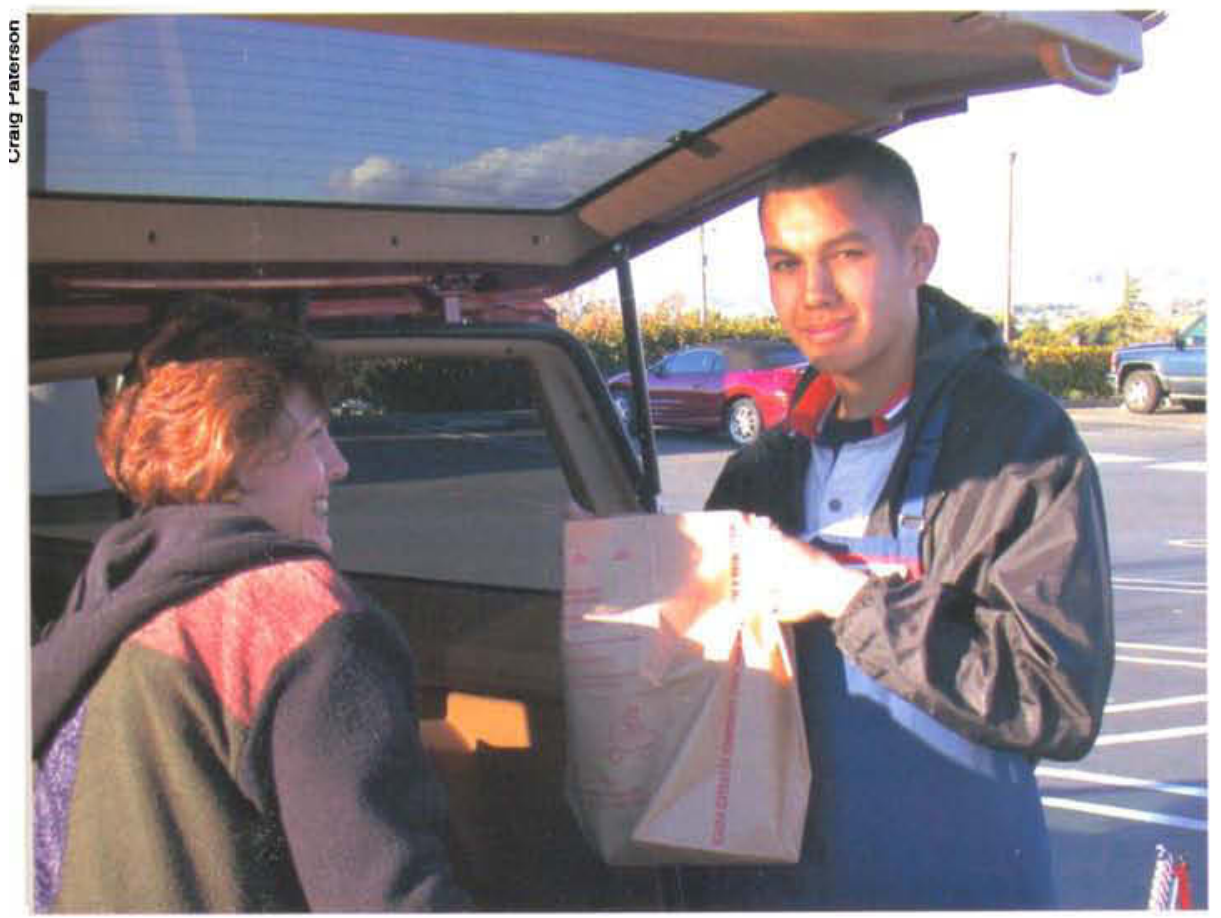

A study of career awareness among Northern California high school seniors found that working part-time was linked to a greater likelihood of believing one's future career is an important consideration during senior year. Kevin Fontanoz, a senior at Hogan High School in Vallejo, works as a courtesy clerk at Safeway. He plans to attend college after graduation.
In a survey of career awareness among high school seniors in Northern California, almost all students agreed that career is an important consideration for them, and about two-thirds reported that they had decided on an occupational field. However, only about half reported that they were comfortable with their current career decision-making, had a clear idea of their own interests and abilities, or had sufficient knowledge about potential occupations. Minority students tended to express greater needs with regard to career exploration than white students. Compared to other groups, significantly fewer Latino males had made an occupational decision. Part-time work during the students' senior year did not appear to hinder school grades or school engagement. In fact, working was associated with generally higher levels of career awareness, especially regarding the importance of career planning. However, part-time work was associated with increases in reported stress levels.
The end of high school constitutes a 1 major transition in the lives of adolescents. Whether they plan to move on to work, college or another post-high school alternative, it is beneficial for students to make active, informed decisions about their ultimate career paths. Unfortunately, many youths approach high school graduation poorly prepared for this transition. In this report, the second of two from our investigation of work transitions of high school seniors in Northern California (see p. 48), we examined students' career awareness, and the potential benefits and drawbacks of part-time work.

We surveyed 1,433 seniors in nine Northern California high schools during spring 1997. Students completed a 17-page questionnaire, containing multiple scales and item formats, in a single class period. The questionnaire inquired about demographic background factors, an estimate of their grade point averages (GPA) and current work experiences. The students also completed a multidimensional scale called the Career Decision Profile (CDP), which enabled us to examine a number of facets regarding their awareness of and priorities for their future careers.

We use the term career awareness to refer to adolescents' reflectiveness about their future work lives. This may or may not include a specific career decision, in which a student can identify with certainty the career field that he or she wants to pursue. However, our definition does include students' active consideration of the elements upon which a decision can be based, such as understanding one's own talents and interests or understanding the opportunities and requirements of various career fields. 


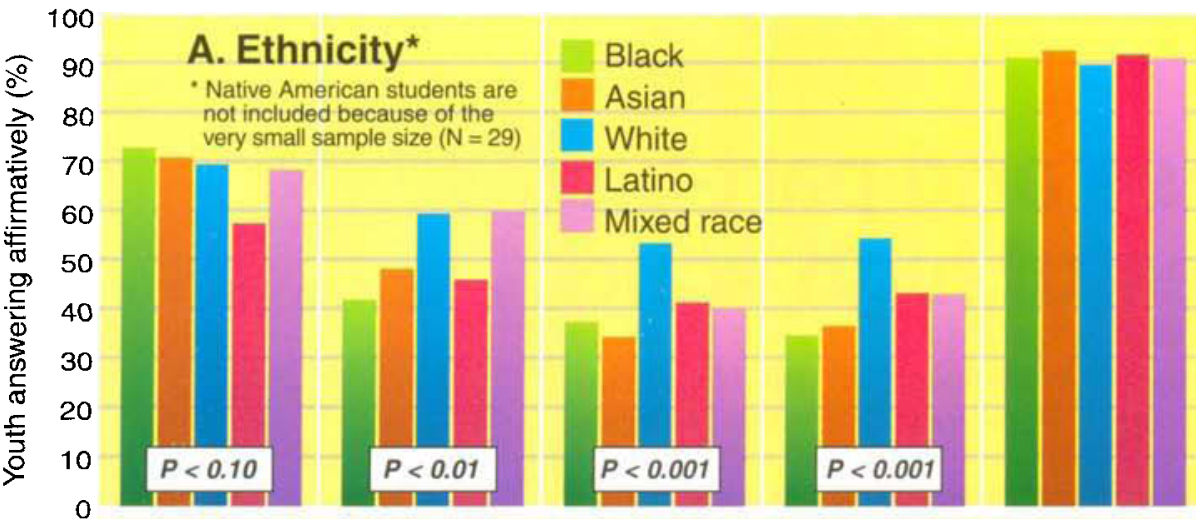

Fig. 1. Relationship of (A) ethnicity, (B) annual household income, (C) grade point average (GPA), and (D) current academic year work to students' self-assessed career awareness characteristics. Listed $\boldsymbol{P}$ values are based on chi-square statistical tests crossing each demographic characteristic (e.g., ethnicity) with each career awareness variable, expressed dichotomously.
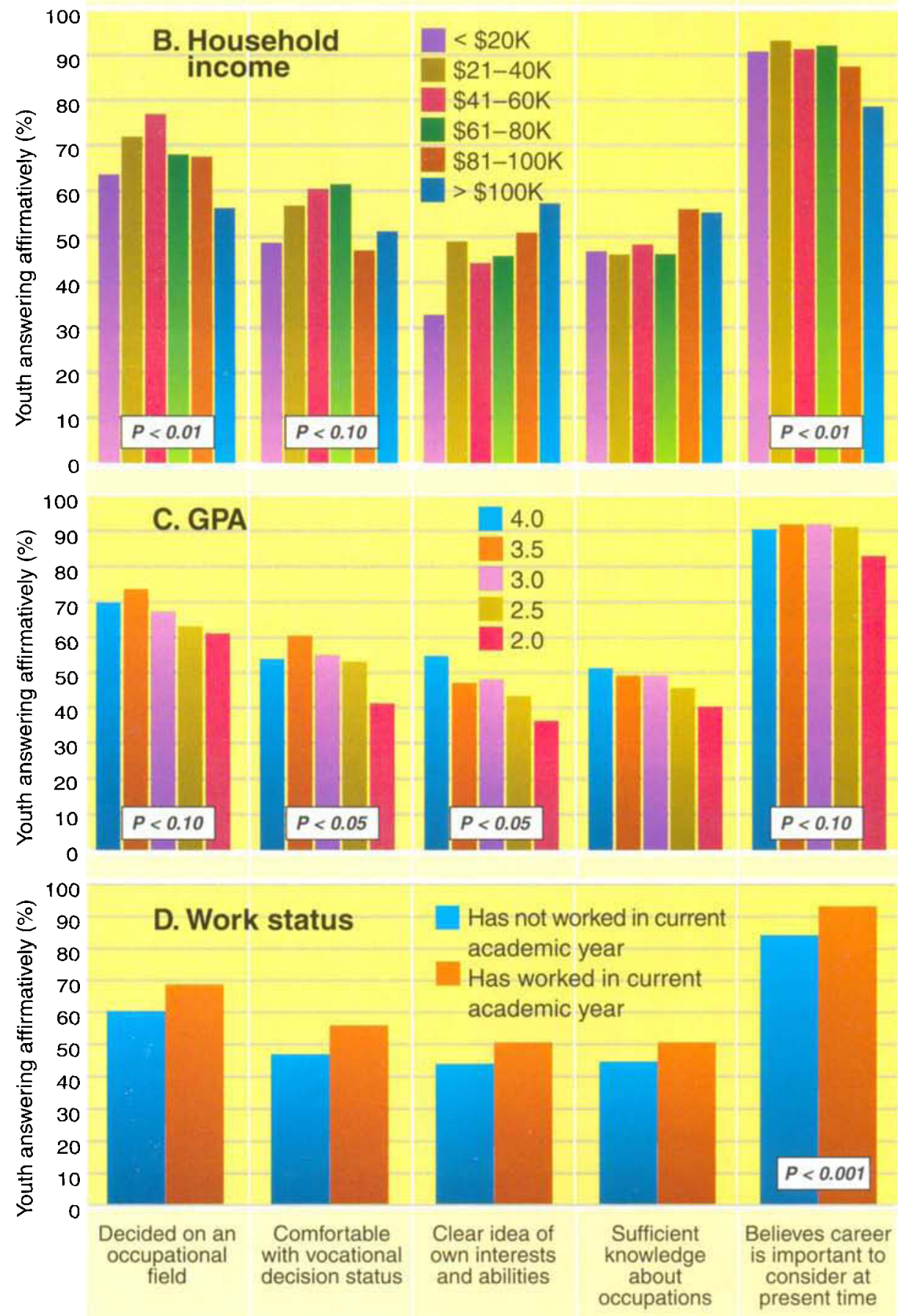

Career awareness characteristics

Developmental research suggests that it is not necessarily desirable or undesirable for a young person to have decided on a career choice while still in high school (Silbereisen et al. 1997). It may be quite appropriate for one individual to decide relatively early and for another to delay the decision. However, whatever their current level of commitment to a specific career field, high school students should be engaged in an exploration process relating to potential careers and vocational identities (Vondracek 1993). This exploration will enable them to make informed choices, whether those choices involve higher education or entry into the workforce. By examining whether students have decided on an occupational field, along with the reasons behind their decision or lack of decision, we can build a more complete picture of their vocational development at the current time.

\section{Measuring career awareness}

We included the CDP (Jones 1989) as part of the survey materials in order to explore the students' career decision status. This instrument has six subscales that measure the students' self perceptions on the following characteristics:

- "Decidedness" regarding their occupational choice ( 2 items).

- Level of comfort regarding that vocational decision status ( 2 items).

- Clear idea of their own interests and abilities ( 3 items).

- Sufficient knowledge about occupations (3 items).

- Belief that their career is important to consider at the present time (3 items).

- Comfort in making decisions in general ( 3 items). 
Each item presents a statement to which students respond on a scale of 1 (strongly disagree) to 8 (strongly agree), and the individual item scores are summed to provide a total score for each subscale. We report here on only the first five subscales, as we judged the general decisiveness scale to have limited relevance for our current discussion.

To facilitate our data analysis, we divided the students' total scores for each CDP subscale into two groups: those who generally tended to agree with the item statements (average item score of 5 or higher) and those who tended to disagree (average item score lower than 5). This process enabled us to classify students as generally decided or undecided on their future occupations, comfortable or uncomfortable with that decision status, clear or unclear about their vocational interests, and so on. In trying to understand what kinds of support can be helpful to adolescents in the career exploration process, we are particularly interested in the total pattern of students' responses across scales; that is, whether they feel comfortable or worried regarding their current vocational decision, their assessments of their knowledge about themselves and the occupational world, and the degree of importance they place on career considerations. These patterns are more informative than the single question of whether students are decided or undecided about their occupational field.

\section{Career awareness levels vary}

About two-thirds of high school seniors reported being decided, to at least some degree, on their occupational field (table 1). However, only slightly more than half reported being comfortable with their decision status. Furthermore, slightly less than half felt they had a clear idea of their interests and abilities or sufficient information about occupations. The overwhelming majority $(90.8 \%)$ felt that it was important to consider their future work at the present time. There was no significant difference between males and females and comfort level, but

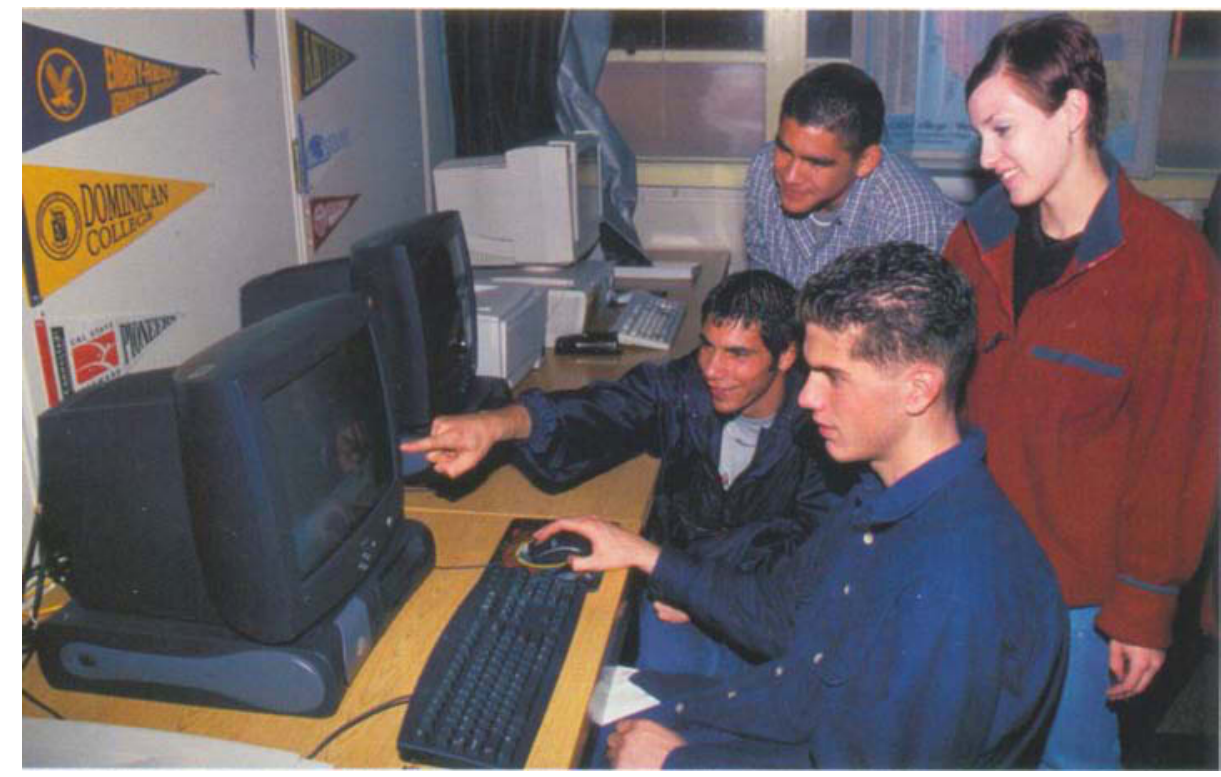

School-based career guidance programs should focus on helping youth to understand themselves as well as the world of work. The Vacaville High School career center provides up-to-date resources such as college catalogs and software, scholarship information, speakers and mentors from the local business community. Clockwise from front: Students Dustin Clark, Jeff Motta, Carlos Rodriguez and Amanda Dietrich.

significantly more males than females reported feeling clear about their own interests and abilities ( $49.4 \%$ versus $42.5 \%$ ), as well as having adequate knowledge about occupations to support a career decision $(50.9 \%$ versus $42.8 \%$ ). These data don't address whether the boys' greater confidence in these areas can be objectively justified. Significantly more females than males $(93.8 \%$ versus $87.6 \%$ ) reported that career considerations are important for them at the present time.

Ethnicity and gender. Minority students (black, Asian, Latino and mixed race) appeared to express greater needs with regard to support in career planning than the white students in our sample (fig. 1A). While the great majority of students in all ethnic groups (between $89 \%$ and $93 \%$ ) believed that career planning is important in their senior year, black, Asian and Latino students all expressed less comfort with their current vocational decision status, less clarity about their own interests and abilities, and less knowledge about occupations than white students.

In addition, whereas most groups were about equal in the percentage that had decided on an occupational field (between $68 \%$ and $73 \%$ ), Latino youths were a significant exception at $57.4 \%$. Further examination revealed a striking gender difference: While $65.2 \%$ of Latina girls were decided - a figure that is only slightly lower than the percentages for other groups - for Latino boys the corresponding percentage was 44.8 , far below any other ethnicity-gender category. Among the Latino students, then, boys and girls differed from each other by more than 20 percentage points, whereas in all other ethnic groups the difference between genders was less than 6 points.

Household income. Surprising results were also found with respect to self-reported household income. The students who were most decided and most comfortable with their decisions were those with household incomes in 
the range of $\$ 20,000$ to $\$ 60,000$ (fig. 1B). Students in the lowest income category (less than $\$ 20,000$ ) tended to be less decided on their future occupations and less comfortable with their decision status. Furthermore, low-income students reported the lowest levels of self-clarity but relatively moderate levels of occupational knowledge and career choice importance. On the other hand, high-income students - especially those from households over $\$ 100,000$ - reported low levels of decidedness and low levels of comfort. While the high-income students reported high self-clarity, high occupational knowledge and moderate decisiveness, they were the lowest of all groups, by far, on the importance they placed on current career planning.

These results regarding household income level are intriguing. Students in the middleincome brackets appeared to have the highest concerns about their careers, suggesting that a moderate level of family income might contribute to some perceived economic pressure that sharpens young people's awareness of career preparation issues. On the other hand, high family income appears to relieve students of the need to be concerned about this topic, resulting in lower priority ratings for career considerations.

Grades. As might be expected, grades were associated with career preparation (fig. 1C). Students reporting GPAs of approximately 3.5 (A's and $B^{\prime}$ s) appeared to be the most career-aware, with the highest percentages of any group on both decidedness and comfort level. Students with GPAs of about 4.0 (usually all $A^{\prime}$ s) were fairly close behind, and students with GPAs of 3.0 (mostly B's) and below displayed a fairly linear descending pattern. Students in the highest grade category reported the highest self-clarity. Scores on occupa-

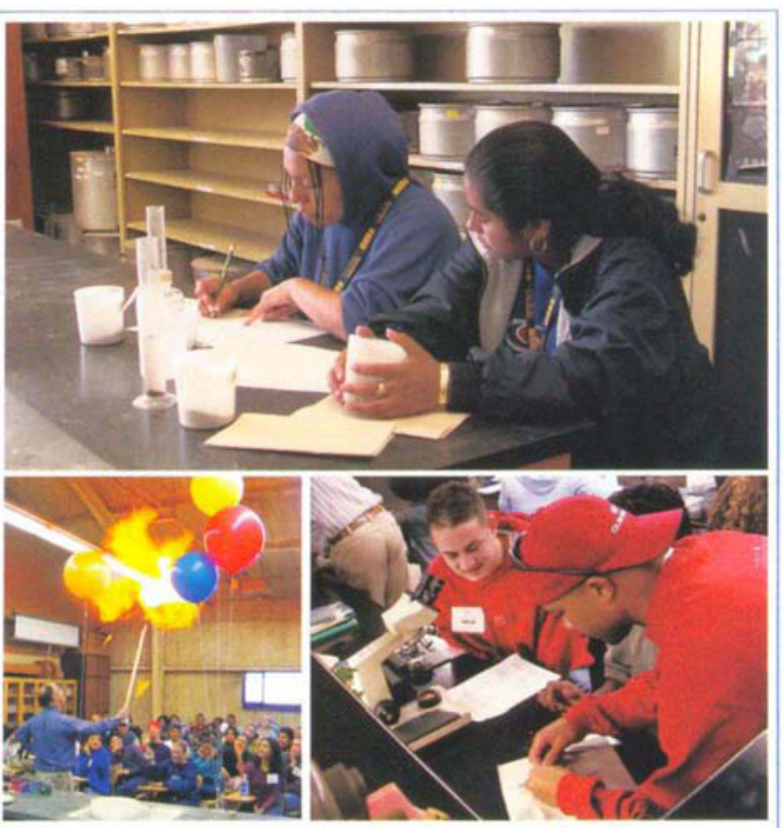

Across the nation, unique partnerships are being formed to better understand the workforce preparation needs of young people and guide them into productive careers. UC's statewide Mathematics, Engineering and Science Achievement (MESA) program has become a model for programs in seven other states and recently received a grant to expand nationwide. The MESA Agricultural Initiative is funded by UC and based at California Polytechnic University, San Luis Obispo, with the goal of getting precollege students interested in careers in agriculture. Top, Middle school students participate in the Junior MESA Soil Science Contest at Cal Poly; left, Cal Poly senior Tony Marshall helps a visiting high school student dissect a mouse; right, Phil Bailey demonstrates chemistry principles. Photos by Bret Harrison.

The low rate of occupational decisions found among male Latino students deserves particular attention. Although, as we noted, a decision on occupation is not necessarily a desirable goal for high school students, the total pattern of response for these youth - in which low decidedness is accompanied by relatively low prevalences of comfort level, perceived self-clarity and occupational knowledge - suggests that they need better assistance than they currently receive in critical developmental tasks related to career exploration.

The results also demonstrate that approaches to career guidance should be sophisticated enough to address the varying patterns of need among students. For example, adolescents who feel they know their chosen field require different types of support than those who are at an earlier stage in the career planning process. Guidance programs, both within and outside of school set-

tional knowledge and general decisiveness were statistically about equal across groups. Career choice importance was also about equal, except for students in the lowest grade category who reported the lowest levels of importance.

Career guidance programs. Based on the students' self-perceived needs, these findings highlight the strong need for greater support of career exploration and planning processes for adolescents, particularly those from minority populations. These processes must focus on helping youths understand themselves as well as the work world. The students' responses suggest that they would be very receptive to reliable sources of information, such as information that can be provided in school-based career guidance programs. The fact that the school programs are underutilized should prompt educators to reexamine those programs and the approaches used to reach and engage students (see p. 48). tings, need to ascertain whether they provide a sufficiently tailored approach.

\section{Part-time work during high school}

The great majority of U.S. adolescents work for pay at some point during their high school years (Mortimer and Johnson 1998). Given the recognized importance of preparing adolescents for the work world, the prospect of employment during high school is often viewed as a valuable opportunity. Many adults believe that parttime work exposes youths to the real-world necessities involved in getting and keeping a job, helps them learn the value of punctuality and other self-organizational skills, and helps them develop personal interaction skills from relating to coworkers.

However, there are potential costs involved. Several studies have documented negative effects on schooling such as reductions in time spent on homework and reduced school en- 


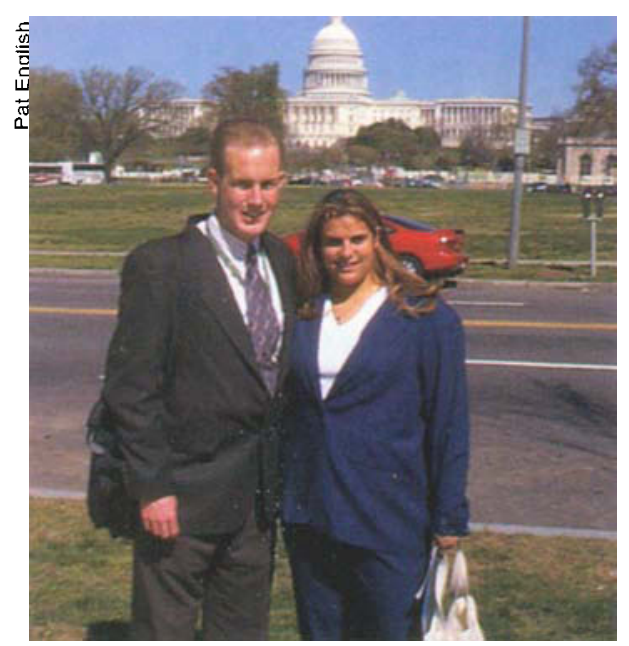

Youth group programs and activities can introduce students to a wider range of opportunities. Jack Crane and Cassandra Barajas were among a group of high school students from California who attended the 4-H National Conference in Washington, D.C.

gagement, higher daily stress levels, and increased exposure to alcohol and drug use in the workplace (Bachman and Schulenberg 1993; Steinberg et al. 1993). A critical factor in this doubleedged relationship is the number of hours worked. Students who work more than 15 to 20 hours per week are particularly susceptible to becoming disengaged from school and more involved with problem behaviors. Students who work fewer hours per week generally show fewer difficulties in balancing school and work. In fact, Mortimer and Johnson (1998) found that high school seniors working fewer than 20 hours per week had higher grades than their peers who either worked more than 20 hours or did not work at all. In sum, then, although the research literature is generally consistent on the detrimental effects of heavy part-time workloads, there is still some disagreement regarding the overall advisability of working less than 15 to 20 hours per week.

We asked our student survey respondents a number of questions relating to their work experience, including whether they had worked at all in the current school year, the number of hours and the type of work. Overall we examined the effects of part-time work in terms of school, perceptions of cost and benefit, and career awareness.

As has been noted in other studies, we found in our survey that most high school seniors worked. In the full sample, $78.5 \%$ of the students reported having worked for pay in a structured setting at some point in time, and $58.6 \%$ reported having done so during the current academic year. Working during the current academic year was not statistically related to either income level or ethnicity, but it was significantly related to gender, with more females $(62 \%)$ than males $(54 \%)$ having worked (chi-square $=6.73, P<$ $0.01)$.

With regard to grades, working students did not at all tend to be the lowest school achievers, as grades were not statistically related to either "ever worked" status or current-year work status. In fact, the highest percentage of current-year employment (56.9\%) was found among students reporting a GPA of 3.5 and the lowest percentage of employment $(48.5 \%)$ was found among students reporting GPAs of 2.0 or lower.

However, as noted in previous studies, a critical factor is not merely whether students work but how many hours. Therefore we compared the GPAs of students in five categories: not working in current academic year, or working 1 to 5,6 to 10,11 to 15 , or 16 or more hours. There was no statistically significant relationship between the number of hours students worked each week and their GPAs. In fact, nonworking students reported a mean GPA essentially equivalent to those working 16 hours or more (3.02 versus 3.01 , although the middle groups showed slightly more variability).

We also looked at students' school engagement, using a scale with six items (for example: "I enjoy going to school"; "I have a hard time caring about much of the material in my classes" [scored in reversed direction]). The range of possible school engagement scores was 0 (low) to 15 (high), and the mean of the overall sample was 10.70 . Once again, this variable was not statistically related to work status. Overall, then, we found absolutely no evidence that students' part-time work is detrimental to school achievement or school engagement.

We next examined whether students' work status might be associated with differences in career awareness. Students who worked during the current year were compared with those who did not work on the five careerawareness variables described previously (fig. 1D). Slightly higher percentages were found for working students on four of the variables, reaching marginal statistical significance with $P$ values between 0.06 and 0.09: occupational decidedness, comfort level with current vocational decision status, self-clarity about interests and abilities, and sufficient occupational knowledge. In addition, a highly significant difference $(P<$ $0.001)$ was found for students' belief that career is important to consider at the present time: A greater percentage of the working students responded that it was important. Overall, these results suggest that the students who worked in their senior year were more

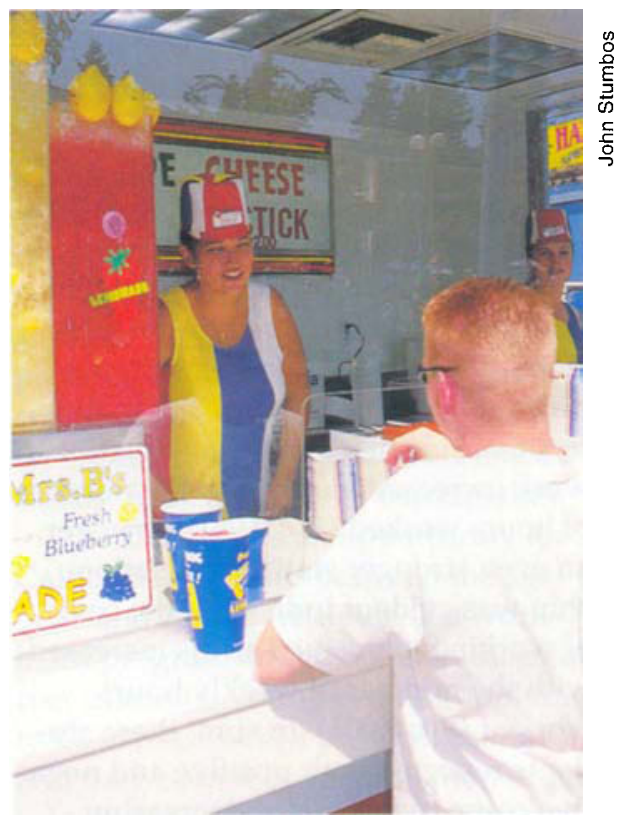

The great majority of high school students work for pay at some time. The study found that part-time work was not detrimental to students' grades or engagement with school. Stress levels were, however, correlated with the number of hours worked. Above, A young person works at the California State Fair in Sacramento. 


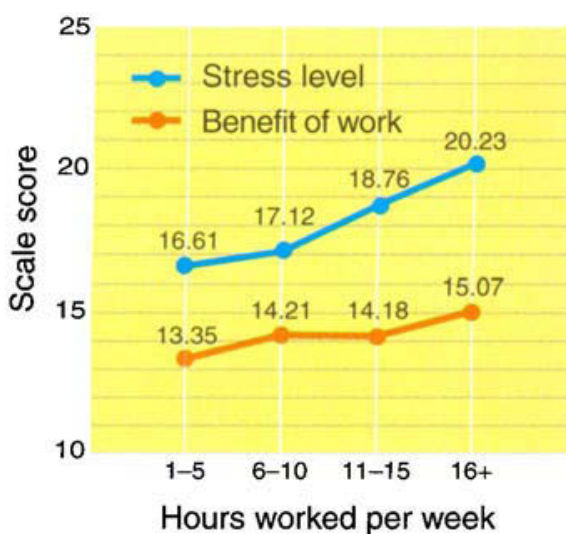

Fig. 2. Relationship of work level to stress and perceived work benefit. Scale range for benefit of work: 0 (lowest) to 24 (highest). Scale range for stress level: 5 (lowest) to 38 (highest).

active in exploring career options and more convinced of its importance.

Finally, we looked at students' perceptions of working. For this purpose we developed two scales, one with 11 items pertaining to stress at work (sample items: "Because of my job, I come to school tired"; "Being a worker and student is stressful") and one with eight items pertaining to the potential benefits of working (sample items: "Working has helped me develop my ability to be on time"; "Working has helped me feel positive about myself and my abilities"). Only students who reported working during the current academic year answered these questions. We found two statistically significant linear trends (fig. 2). On the positive side, the perceived benefits of work increased along with the number of hours worked $(P<0.05)$. However, an even stronger statistical relationship was evident indicating the costs of working: perceived stress increased with the number of weekly hours worked $(P<0.001)$. In sum, these students reported both positive and negative consequences of an increasing level of part-time work.

Our findings suggest that part-time work is generally not detrimental to other areas of students' lives. The students who worked in their senior year did not appear to be hindered in their grades or engagement with school. They perceived benefits to their work experiences, and even appeared to be somewhat more attuned to tasks related to career development. The one negative finding associated with parttime work was that students' stress levels increased as well. The level of stress reported was directly related to the number of hours worked per week, suggesting that the students may have been experiencing some difficulty in balancing demands of different parts of their lives.

A critical question voiced by researchers is whether the negative findings often associated with part-time work are due to the work experience itself or to a self-selection process, in which students who are lagging academically simply enter the workforce at an earlier age than their classmates. Some studies have found that both processes are operative: students who work long hours are indeed different from their peers even before their work experience, but the work experience can exacerbate the existing risks and accelerate the disengagement from school (Bachman and Schulenberg 1993). However, there is also general agreement that one cannot make sweeping statements applying to all students in this age group. Some students thrive with additional work responsibilities while others find it difficult to strike a successful balance. Furthermore, work experiences will be more valuable for adolescents if some degree of complexity and autonomy can be incorporated into the work tasks (Vondracek 1993).

\section{Need for career preparation}

Our study's results confirm that there is a clear need for more effective career preparation programs for young people. Nationwide over the past several years, the Cooperative Extension System has played a leading role in providing informational outlets to educators and youth programmers regarding current ap- proaches and federal recommendations for workforce preparation. The topic of career preparation will undoubtedly occupy the national spotlight in coming years, as the complexity and rate of change in the modern workplace continue to accelerate.

M.T. Braverman is 4-H Youth Development Specialist, Department of Human and Community Development, UC Davis; J. Chin Young is 4-H Youth Development Advisor, UC Cooperative Extension (UCCE), Marin County; N.J. King is Youth and Family Development Specialist, College of Agricultural and Environmental Sciences, UC Davis; C.A. Paterson is $4-H$ Youth Development Advisor, UCCE Solano County; and R.S. Weisskirch is Assistant Professor, California State University, Monterey Bay. The UC Division of Agriculture and Natural Resources provided funding for this study.

\section{References}

Bachman JG, Schulenberg J. 1993. How part-time work intensity relates to drug use, problem behavior, time use, and satisfaction among high school seniors: Are these consequences or merely correlates? Dev Psychol 29(2):220-35.

Jones LK. 1989. Measuring a three-dimensional construct of career indecision among college students: A revision of the Vocational Decision Scale - The Career Decision Profile. J Counsel Psychol 36(4):477-86.

Mortimer JT, Johnson MK. 1998. Adolescent part-time work and educational achievement. In: Borman K, Schneider B (eds.). The Adolescent Years: Social Influences and Educational Challenges; 97 th yearbook of the $\mathrm{Na}$ tional Society for the Study of Education. Chicago: Univ Chicago Pr. p 183-206.

Silbereisen RK, Vondracek FW, Berg LA. 1997. Differential timing of initial vocational choice: The influence of early childhood family relocation and parental support behaviors in two cultures. J Voc Behav 50(1):41-59.

Steinberg S, Fegley S, Dornbusch SM. 1993. Negative impact of part-time work on adolescent adjustment: Evidence from a longitudinal study. Dev Psychol 29(2):171-80.

Vondracek FW. 1993. Promoting vocational development in early adolescence. In: Lerner RM (ed.). Early Adolescence: Perspectives on Research, Policy and Intervention. Hillsdale, NJ: Erlbaum. p 277-92. 